\title{
Retratos da reforma psiquiátrica: aproximações entre Brasil e Espanha
}

\author{
Portraits of Psychiatric Reform: approximations between Brazil and Spain
}

Rafael Nicolau CARVALHO*

https://orcid.org/oooo-00o1-9636-6071

\section{Antonia Picornell-LUCAS**}

https://orcid.org/oooo-0oo2-1735-6666

Resumo: Este artigo apresenta uma análise qualitativa das experiências de desinstitucionalização no Brasil e na Espanha, de modo a construir retratos dos processos de reforma psiquiátrica, dentro de um contexto recente de crise que ameaça os princípios reformistas. Para a realização deste estudo, utilizouse a revisão bibliográfica narrativa e a pesquisa documental. As análises indicaram que apesar das particularidades históricas e culturais e das diferenças nos arranjos organizacionais da atenção psicossocial que permeiam as experiências nestes países, ambos adotam a desinstitucionalização como principal característica de seus processos de reforma. Conclui-se que, na atual conjuntura, o projeto contemporâneo de reforma enfrenta três grandes desafios: desmontar a estrutura manicomial, fortalecer o modelo de atenção psicossocial e combater a lógica asilar.

Palavras-chave: Reforma Psiquiátrica. Desinstitucionalização. Saúde Mental.

Abstract: This article presents a qualitative analysis of the deinstitutionalization experiences of Brazil and Spain to build a picture of the psychiatric reform processes within the context of a recent crisis that threatens reformist principles. The study was based on a narrative bibliographic review and documentary research. The analysis suggests that despite the historical and cultural particularities and differences in organizational arrangements for psychosocial care that permeate these countries, both have adopted deinstitutionalization as the main characteristic of their reform processes. It concludes that, currently, the contemporary reform project faces three major challenges: the dismantling of the asylum structure, strengthening the model of psychosocial care, and fighting the asylum logic.

Keywords: Psychiatric Reform. Deinstitutionalization. Mental Health.

Submetido em: 29/3/2020. Aceito em: 11/8/2020.

\footnotetext{
* Assistente Social. Doutor em Sociologia. Professor adjunto do Departamento de Serviço Social da Universidade Federal da Paraíba (UFPB, João Pessoa, Brasil). Cidade Universitária, s/n, CEP.: 58.051900 João Pessoa (PB). O presente trabalho foi realizado com apoio da Coordenação de Aperfeiçoamento de Pessoal de Nível Superior - Brasil (CAPES) - Código de Financiamento o01. E-mail: rafaeljp.carvalho@gmail.com.

** Assistente Social. Professora Titular do Departamento de Derecho de Trabajo y Trabajo Social da Universidad de Salamanca (USAL). Doutora em Educação pela USAL. Professora Visitante na Universidade Federal da Paraíba no Programa de Pós-Graduação em Serviço Social (UFPB, João Pessoa, Brasil). Cidade Universitária, s/n, CEP.: 58.051-900 João Pessoa (PB). E-mail: toi@usal.es.
} 


\section{Introdução}

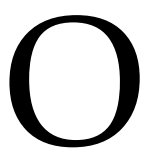

projeto contemporâneo de reforma psiquiátrica é caracterizado pela crítica ao modelo clássico de tratamento das pessoas com transtornos mentais, denominado modelo asilar, que foi consolidado pela psiquiatria tradicional. Assim, para uma melhor apreensão dessa crítica, serão feitos previamente alguns comentários sobre as principais categorias relacionadas com a construção histórica da reforma psiquiátrica, a saber: a ideia de doença mental, a crítica ao modelo asilar, e as estratégias de desinstitucionalização.

A definição da doença mental como objeto da medicina data do final do século XVIII, e remete particularmente à experiência de Philippe Pinel no Hospício de Bicêtre, na França, e à publicação de sua obra clássica Tratado Médico-filosófico sobre Alienação Mental e Mania, quando capturou a experiência da loucura e a classificou como uma doença de ordem moral, denominando-a de alienação mental. Sua obra é considerada a principal fundadora da especialidade psiquiátrica, lançando as bases do que se conhece por modelo asilar, pois foi Pinel que determinou o isolamento como necessidade para o tratamento moral do alienado mental (AMARANTE, 2017).

Esse processo de definição da doença mental ganhou maior relevância no século XIX, a partir da consolidação da psiquiatria como campo específico do saber, que encarcerou a experiência da loucura no signo da doença mental e estabeleceu a intervenção no doente mental como objeto de sua prática. Essa mudança paradigmática propiciou à psiquiatria o desenvolvimento de seu aparato institucional e de suas tecnologias (PINHO; BAÑON HERNÁNDEZ; KATORSKI, 2010).

Sobre essa práxis, Costa-Rosa (2000) declara que o modelo asilar produz a ruptura dos vínculos familiares das pessoas com transtornos mentais, em proveito de um processo de adestramento e aprendizagem que só poderia ser efetivado pela submissão às rígidas regras e rotinas das instituições manicomiais. Foi a partir desta concepção que o saber médico-psiquiátrico, afiliado às tecnologias de isolamento, definiu o modelo asilar como forma de tratamento do doente mental (ALVES, 2008; COSTA-ROSA, 2000). Modelo que responde pela proliferação de instituições asilares nos diferentes continentes, especificamente na Europa, onde, até meados dos anos 1960, prevaleceu a ideia da necessidade de isolamento dessas pessoas do convívio social, em virtude da suposta periculosidade/marginalidade atribuída à doença e ao doente mental (ALMEIDA FILHO et al., 2015).

Esse modelo aprofundou o processo de exclusão do louco, encarcerando-o em instituições fechadas e submetendo-o a tratamentos degradantes e violentos, como foi registrado em vários países, nos quais se começou a esboçar a crítica - fundada na denúncia dessas práticas - ao modelo asilar e ao saber da psiquiatria sobre a loucura. Crítica esta acompanhada de propostas para um projeto contemporâneo de reforma psiquiátrica, como aqui denominamos. Vale destacar que o período pós-Segunda Guerra foi considerado importante para o desenvolvimento do referido projeto, em virtude da analogia entre os horrores produzidos nos campos de concentração nazistas e os grandes manicômios existentes em alguns países europeus (AMARANTE, 2018). 
A proposta dos movimentos de reforma foi modificar o tratamento das pessoas, retirando-as do isolamento, proporcionando-lhes um atendimento digno e procedimentos terapêuticos adequados; "[...] eram os primeiros movimentos para a desinstitucionalização" (SIQUEIRA-SILVA; NUNES; MORAES, 2013, p. 477).

A desinstitucionalização foi o conceito básico incorporado pelos projetos de reforma, moldando as políticas de saúde mental desenvolvidas em vários países, incluindo o Brasil. O termo teve sua origem no movimento de reforma psiquiátrica na Itália, nos anos 1970, que influenciou fortemente o movimento brasileiro pela reforma psiquiátrica (AMARANTE, 2018).

No âmbito da saúde mental, a expressão desinstitucionalização remete à crítica epistemológica ao saber médico-psiquiátrico, constituindo-se principal fundamento do projeto de reforma, bem como a reconfiguração das práticas em saúde mental com o deslocamento da assistência para o território e a comunidade, perspectiva adotada pelo movimento brasileiro.

Nessa acepção, a desinstitucionalização representa o princípio norteador da reforma e das políticas de saúde mental. Ao assumir essa perspectiva, os diversos países instauram a proposta de um conjunto de iniciativas sociais, políticas, administrativas e culturais, cujo objetivo é transformar o aparato manicomial instalado pela psiquiatria e provocar mudanças na forma como a sociedade, historicamente, relaciona-se com o fenômeno da loucura, além de propiciar a construção de novos saberes sobre os transtornos mentais (ALMEIDA FILHO et al., 2015; AMARANTE, 2018).

Levando em consideração esse debate, o estudo que dá origem a este artigo objetivou analisar as experiências de desinstitucionalização no Brasil e na Espanha, buscando construir retratos do processo de reforma psiquiátrica e, particularmente, averiguar as estratégias de organização da rede a partir da análise de documentos legais, considerando o contexto recente de crise que ameaça os princípios reformistas.

Os referidos países foram designados como campo privilegiado para realização da pesquisa, por conterem elementos sociais e históricos semelhantes nos seus processos de reforma psiquiátrica, uma vez que partilham da crítica ao modelo asilar e, na trajetória de implementação das suas respectivas redes de atenção à saúde mental, têm incorporado a desinstitucionalização como eixo norteador. Ademais, assim como no Brasil, a Espanha vem passando por um retrocesso no tocante às políticas sociais, agravado pelas políticas neoliberais como a participação de entidades privadas na gestão dos serviços sanitários e ataques à rede de atenção psicossocial, com ênfase na atenção ao Transtorno Mental Grave (TMG) e à restrição de recursos para os serviços comunitários e territoriais (DESVIAT, 2016).

Este trabalho é procedente das primeiras reflexões e de contatos com os contextos de pesquisa do projeto intitulado Análise das experiências de Reforma Psiquiátrica no Brasil, Espanha e Portugal: um estudo descritivo sobre as políticas de desinstitucionalização, desenvolvido com apoio da Coordenação de Aperfeiçoamento de Pessoal de Nível Superior (Capes). 
Com isso em mente, na seção Método, apresentam-se inicialmente notas metodológicas sobre o processo de construção desta análise. Na seção seguinte, analisa-se o processo de Reforma Psiquiátrica no Brasil, destacando-se os avanços de sua implantação e os desafios na conjuntura recente. Em seguida, contextualiza-se a Reforma Psiquiátrica na Espanha, apontando-se também as dificuldades para a sua consolidação e a organização da rede de saúde mental.

\section{Método}

O estudo em tela é uma síntese reflexiva, resultado de uma revisão bibliográfica narrativa e de uma pesquisa documental. A revisão narrativa caracteriza-se por uma abordagem mais ampla do tema e tem como objetivo descrevê-lo e discuti-lo em um dado contexto. Este tipo de revisão procura responder às questões gerais de estudo, de modo a possibilitar ao pesquisador uma visão do estado da arte daquele assunto, não possuindo uma metodologia definida. Esta abordagem difere da revisão bibliográfica sistemática, cujos critérios de seleção e avaliação do material levantado são específicos. A análise produzida pela revisão narrativa é essencialmente qualitativa e apresentada em forma de síntese (ROTHER, 2007).

Nesse sentido, buscou-se levantar artigos científicos e outras produções relevantes, consideradas referências, para a contextualização do processo de reforma em ambos os países. Com relação aos artigos científicos, foi realizada uma busca na base de dados institucional da Universidade de Salamanca utilizando-se os descritores reforma psiquiátrica e desinstitucionalização, em português e espanhol. Inicialmente, procedeuse a leitura dos títulos e resumos dos artigos levantados para verificar a pertinência do texto, considerando o objetivo de contextualizar o processo de reforma. Em seguida, realizou-se um conjunto de leituras do material selecionado, conforme sinaliza Lima e Mioto (2007), a saber: leitura seletiva, a fim de definir as informações relevantes; leitura reflexiva ou crítica, buscando compreender os pontos de vista dos autores; e a leitura interpretativa, entendida como um momento de relacionar as ideias com o propósito do estudo e a possibilidade de estabelecer comparações. Tais leituras possibilitaram uma compreensão do desenvolvimento do processo de reforma, bem como sua contextualização na presente síntese. Consideraram-se como produções relevantes as obras de Amarante (2017, 2018) e Desviat (2015, 2016), pela significativa contribuição desses autores na análise e sistematização do processo de reforma no Brasil e na Espanha, respectivamente. Outros textos foram utilizados para fundamentar as relações entre os conceitos e elementos contextuais que foram surgindo no momento da interpretação.

A pesquisa documental foi guiada de forma a buscar elementos para a caracterização do processo de reforma em si, bem como da organização da rede de saúde mental em ambos os países. Assim, foram selecionados documentos que implicassem a superação do modelo asilar e a organização da rede de saúde mental com base na desinstitucionalização. Os documentos considerados para o contexto brasileiro foram a Lei $n^{\circ}$ 10.216/o1 (BRASIL, 2001), conhecida como Lei da Reforma Psiquiátrica Brasileira; a Portaria ${ }^{\circ}$ 336/o2 (BRASIL, 2002), que estabelece os Centros de Atenção Psicossocial (CAPS) como principal dispositivo da rede de saúde mental; a Portaria $\mathrm{n}^{\circ}$ 3.088/11 
(BRASIL, 2011), que institui a Rede de Atenção Psicossocial (RAPS); e a Norma Técnica no 11 de 2019 (BRASIL, 2019), que consolida as mudanças recentes promovidas na política de saúde mental brasileira. Outros documentos foram arrolados, como o relatório $\mathrm{n}^{\circ} 12$ do Ministério da Saúde (BRASIL, 2015) intitulado Saúde Mental em Dados. Para o contexto Espanhol, seguindo os mesmos critérios, foram considerados: o Informe para a Reforma Psiquiátrica (ESPANHA, 1985), que direciona o modelo de assistência em saúde mental; a Lei Geral de Saúde (ESPANHA, 1986), que garante a atenção à saúde mental no âmbito comunitário; a Estratégia em Saúde Mental do Sistema Nacional de Saúde (ESPANHA, 2007), bem como o seu relatório de avaliação (ESPANHA, 2010) e a edição da segunda estratégia para o período de 2009 a 2013 (ESPANHA, 2011). Todos os documentos foram coletados em bases de dados oficiais.

Os dados foram extraídos dos documentos e organizados em um quadro síntese com três categorias, a saber: contextualização do processo de reforma, estratégias de organização da rede, mudanças recentes. Para tratá-los, utilizou-se a técnica de análise de conteúdo do tipo categorial-temático.

A partir da reflexão sobre as informações tanto da revisão documental quanto da revisão bibliográfica, foi produzida a presente síntese acompanhada da contextualização do processo de reforma nos dois países.

\section{Avanços e desafios do Projeto de Reforma Psiquiátrica brasileiro}

O modelo brasileiro de assistência psiquiátrica foi historicamente influenciado pelos modelos europeus, desde a origem da psiquiatria nacional ${ }^{1}$ até $\mathrm{o}$ movimento pela reforma. Tais modelos foram incorporados de distintas maneiras, expressando a forma como a loucura foi abordada pelo aparato institucional da psiquiatria.

No Brasil do início do século XX, destacam-se a emergência de duas formas de tratar as pessoas com transtornos mentais: as colônias agrícolas e a assistência psiquiátrica manicomial. Para Silva (2009), estas duas modalidades correspondem a matrizes foucaultianas ao tratar da medicina social: 1) a matriz religiosa, em que o tratamento seria mediante o trabalho rural em contato com a natureza, isolando o indivíduo do seu território e de sua família; e 2) a matriz militar, quando os indivíduos eram mantidos nas casas ou em instituições para higienizar o espaço urbano. Este último modelo marcou profundamente a psiquiatria brasileira, produzindo um grande número de instituições psiquiátricas, como hospitais, manicômios e inúmeras experiências de colônias de alienados em vários estados, os quais, em certa medida, reproduziram os horrores dos campos de concentração nazista, assim apontado por Franco Basaglia, em visita à Colônia de Barbacena-MG, em 1979 (AMARANTE; NUNES, 2018).

Esse paradigma psiquiátrico entra em crise no final dos anos 1970, crise que se prolonga até meados dos anos 8o, refletindo o momento histórico e político que o país atravessava, pois o modelo psiquiátrico não mais respondia às necessidades da

\footnotetext{
${ }_{1}^{1}$ De acordo com Amarante (2017), a assistência psiquiátrica no Brasil começa com a fundação do primeiro hospital psiquiátrico, o Hospício de Pedro II, fundado pelo Imperador, na cidade do Rio de Janeiro, na data de sua sagração, em 1841.
} 
população, que passou a questionar os princípios fundantes do saber psiquiátrico. Este questionamento foi motivado pelas denúncias das condições degradantes a que os indivíduos eram submetidos nas instituições manicomiais e pelos ganhos financeiros das instituições psiquiátricas, provenientes, em grande parte, de internações compulsórias financiadas pelo Estado. Tais ações revelaram o caráter mercantil da estrutura asilar, basicamente privada, que ficou conhecido em nossa história como a indústria da loucura (PITTA, 2011).

Dessa forma, o processo de reforma psiquiátrica brasileiro teve início em um contexto de crítica ao modelo asilar e de emergência dos movimentos pelos direitos das pessoas com transtornos mentais, as quais, além de estigmatizadas e marginalizadas socialmente, eram vítimas de violência e maus-tratos no interior do aparato manicomial. O movimento pela reforma inicia-se, portanto, com uma série de denúncias das violências cometidas nas instituições psiquiátricas que ocasionou a Crise da Dinsam (Divisão Nacional de Saúde Mental), órgão do Ministério da Saúde que coordenava os serviços de saúde mental (AMARANTE, 2017). A partir desse acontecimento, esboçou-se o Movimento dos Trabalhadores em Saúde Mental (MTST), que articulou importantes eventos no âmbito da saúde mental e pautou a luta pelos direitos das pessoas com transtornos mentais.

Na década de 1980, o respectivo movimento passou a denominar-se Movimento de Luta Antimanicomial, e prossegui com uma agenda de mobilizações contra o modelo asilar, reunindo não só trabalhadores, mas pensadores, estudiosos, pessoas com transtorno mental e seus familiares. Nesse período, houve importantes trocas de experiências e conhecimentos com pensadores estrangeiros que muito contribuíram para as análises do processo de reforma, a exemplo do conceito de desinstitucionalização e das referências para atenção comunitária incorporados da Reforma Psiquiátrica Italiana e de experiências inglesas, respectivamente. O próprio Franco Basaglia participou do processo de reforma no Brasil, além de outros importantes interlocutores como Michel Foucault, Erving Goffman e Robert Castel, os quais influenciaram o processo de reforma e contribuíram para adensar as críticas ao modelo asilar (AMARANTE; NUNES, 2018).

O movimento pela reforma avançou até a aprovação da Lei $n^{\circ} 10.216 / 01$, que dispõe sobre a proteção e os direitos das pessoas com transtornos mentais e redireciona o modelo assistencial em saúde mental. A partir da década seguinte, tem-se a implantação da rede de saúde mental, acompanhada por um aparato normativo e institucional.

A atual política de saúde mental brasileira é oriunda desse processo histórico de crítica sistemática ao modelo asilar e da luta pelos direitos das pessoas com transtornos mentais, que culminou com sua materialização no conjunto das políticas públicas de saúde (Política Nacional de Saúde Mental, Política Nacional sobre Drogas, Política de Promoção da Saúde, Atenção Básica, entre outras). Vale ressaltar que tais avanços resultaram do diálogo permanente e da constante reflexão crítica que o movimento promoveu entre as práticas terapêuticas e as experiências de desinstitucionalização, 
desde a instituição do primeiro Centro de Atenção Psicossocial (CAPS), em 1987², até a experiência santista, em $1989^{3}$.

O movimento pela reforma também é parte fundamental no processo de conquista democrática no país, o qual esteve integrado a outros movimentos sociais, como a Reforma Sanitária, que lutou pelo direito à saúde e pela construção do Sistema Único de Saúde (SUS), direito consolidado na Constituição Federal de 1988.

A rede de saúde mental se integra ao SUS a partir das primeiras portarias que regularam as ações de saúde mental ainda nos anos de 1990. Todavia, a expansão significativa destes serviços se efetivou a partir da aprovação da Lei $n^{\circ}$ 10.216/o1 e da Portaria $n^{\circ}$ 336/o2, que passaram a instituir e regular a rede de saúde mental no território nacional. À consolidação e ampliação do novo modelo em saúde mental sucedeu a criação da Rede de Atenção Psicossocial (RAPS) pela Portaria n 3.088, em 2011.

A RAPS, por sua vez, instaura pontos de atenção em saúde mental em vários componentes da rede de saúde, constituindo-se, assim, uma rede integrada de cuidados em saúde mental, adotando como principal estratégia a articulação de diferentes serviços. A Rede incorpora os CAPS e os demais serviços já existentes em um componente de atenção específico, nominado Atenção Psicossocial Estratégica. A Portaria $\mathrm{n}^{\circ}$ 3.088/11 determina ainda que as ações de saúde mental devem ser articuladas a partir da Atenção Básica e com os demais níveis de atenção da rede de saúde, de modo a constituir uma rede integral de cuidado (BRASIL, 2011).

Durante seu percurso, a Reforma Psiquiátrica Brasileira consolidou um processo de transição paradigmática, do modelo asilar para o modelo de atenção psicossocial, com inúmeras conquistas nos últimos 20 anos, como a reversão dos recursos financeiros destinados aos hospitais psiquiátricos (que nos anos 1990 eram cerca de 90\%) para a atenção psicossocial. Em 2005, houve a virada dos recursos financeiros para os serviços substitutivos, quando, pela primeira vez, o governo federal destinou mais recursos para os CAPS (BRASIL, 2015). A partir de 2011, com a instituição da RAPS, logrou-se um significativo aporte de recursos financeiros voltados para a atenção psicossocial, principalmente para a diversificação dos serviços.

Outras importantes conquistas foram obtidas nesse período, dentre elas, destacam-se: a redução de aproximadamente 35 mil leitos em hospitais psiquiátricos e a criação de mais de 2.200 CAPS. Estes números expressam o movimento de deslocamento da lógica da atenção para o modelo de atenção psicossocial; inovações na política de saúde mental brasileira, como as iniciativas do Consultório na Rua, que integra a Atenção Básica no âmbito da RAPS e tem por objetivo o atendimento de usuários de álcool e drogas em situação de rua, articulando os demais serviços da rede; o matriciamento em saúde

\footnotetext{
${ }^{2}$ Criado na cidade de São Paulo pela Secretaria Estadual de Saúde. Trata-se do primeiro serviço fora da lógica manicomial que procurou desenvolver ações no âmbito da comunidade e da assistência às pessoas com quadros graves (AMARANTE, 2017).

3 Fechamento de um hospital psiquiátrico privado pela prefeitura de Santos-SP, a Clínica Anchieta, e posterior implantação de uma série de serviços e projetos de atenção comunitária e psicossocial inspirados pela Reforma Psiquiátrica Italiana. Tornou-se o modelo a ser seguido pela reforma brasileira (AMARANTE, 2017).
} 
mental, que pode ser realizado tanto por equipes do CAPS, equipes volantes de saúde mental, quanto pelas equipes dos Núcleos de Atenção à Saúde da Família (NASF) (BRASIL, 2015; DELGADO, 2015).

Nos últimos anos, no entanto, as políticas de saúde mental vêm sendo inflexionadas pelo contexto político, econômico e social adverso, que tem dilapidado as conquistas provindas do movimento pela reforma e atacado os direitos sociais conquistados no processo histórico de lutas, desvelando uma verdadeira contrarreforma do Estado e provocando impactos profundos no âmbito da saúde mental (FARIAS, 2019).

Essas mudanças, por conseguinte, limitam o aprofundamento do projeto de reforma norteado pela desinstitucionalização, seja pelos ataques aos direitos sociais e o retorno do modelo asilar, seja pelos processos ainda não consolidados no aprofundamento da reforma. Tais situações evidenciam as fragilidades a serem superadas, como, por exemplo, deficiência na estrutura física dos serviços, falta de concursos públicos para contratação de profissionais qualificados, carência de mecanismos de avaliação da rede, desafio na articulação com a Atenção Básica e frágil articulação com os serviços de urgência e emergências, bem como as dificuldades de operacionalização da estratégia da intersetorialidade (BRITO, BONFADA; GUIMARÃES, 2015; DELGADO, 2015).

As Portarias editadas entre 2017 e 2018, consolidadas na Nota Técnica no 11 de 2019, reafirmam modificações na RAPS processadas pelas normas anteriores. Dentre elas, salienta-se a denominação nova RAPS, a qual reconhece o valor terapêutico do hospital psiquiátrico, que volta a fazer parte da Rede, assim como o aumento dos recursos para os hospitais psiquiátricos, a afirmação das comunidades terapêuticas com matiz religioso no trato dos usuários de álcool e outras drogas, o abandono da estratégia de Redução de Danos e o reconhecimento das novas terapias, a exemplo da Eletroconvulsioterapia (ECT) (BRASIL, 2019; FARIAS, 2019; LIMA, 2019).

A mencionada Nota ainda desconsidera o trabalho de matriciamento em saúde mental desenvolvido pelas equipes dos NASF quando sugere a abertura de ambulatórios de saúde mental para casos menos graves, negando o trabalho de integração com a Atenção Básica. A Nota também prevê a internação de crianças e adolescentes em hospitais psiquiátricos, desconsiderando os preceitos do projeto de reforma para a abordagem de problemas de saúde mental na infância e adolescência, assim como o trabalho de integração entre os CAPS infantojuvenis e os demais serviços da rede de saúde, escolas, famílias e rede socioassistencial (BRASIL, 2019; FARIAS, 2019; LIMA, 2019;).

Posto isso, apreende-se que as medidas estabelecidas na Nota Técnica no 11/2019 não promovem apenas o retorno do hospício como oferta de atendimento, mas reforçam a cultura manicomial que sempre esteve presente no imaginário da população, sendo objeto de luta no processo de reversão do modelo assistencial e uma das principais características da desinstitucionalização. 


\section{Contexto da Reforma Psiquiátrica na Espanha}

Na Espanha, o projeto contemporâneo de Reforma Psiquiátrica começa com bastante atraso em relação a outros países europeus (DESVIAT, 2011). Este atraso está relacionado com os 40 anos em que o país permaneceu mergulhado em um regime autoritário, a ditatura do general Francisco Franco (1936-1975). A ditatura franquista teve um caráter extremamente violento e repressivo, o que também isolou o país do contexto internacional, preservando suas características rurais e impactando fortemente o desenvolvimento econômico e social (WOLF; OLIVEIRA, 2017).

Vale destacar que alguns países que promoveram mudanças substanciais na saúde mental estavam sob ditaduras desde os anos 1960 a meados dos anos 1980, apoiadas pelos segmentos mais conservadores da sociedade. Portanto, a construção dos sistemas de proteção social e as reformas pretendidas no âmbito da saúde só foram possíveis com a queda desses regimes e o avanço de grupos progressistas que criaram uma agenda de debates em busca da liberdade e dos direitos sociais (WOLF; OLIVEIRA, 2017).

Nesse sentido, a primeira mudança que favoreceu a reforma foi a transição de um regime ditatorial para um regime democrático, que levou a organização da sociedade espanhola a combater a estrutura do franquismo e a assumir o compromisso com a construção de um sistema de proteção social, o qual teve início com o direito à saúde e a construção do Sistema Nacional de Saúde (SNS). Outro fator de grande relevância foi a entrada da Espanha na União Europeia (UE), em 1986, facultando um aporte significativo de recursos financeiros do fundo comum europeu, mas também a integração do país e de suas políticas às regulamentações e acordos firmados com o bloco (WOLF; OLIVEIRA, 2017).

Em face das ocorrências apontadas, a Reforma Psiquiátrica na Espanha ocorreu no contexto de construção democrática, com a aprovação da Constituição Espanhola de 1978, que garantiu o direito universal à saúde e mudou a forma de prestação dos serviços de saúde, antes centralizados no Estado (DESVIAT, 2015). Semelhante ao processo brasileiro, essa Constituição estabeleceu uma nova estrutura político-administrativa, com base na descentralização das ações, criando, assim, as Comunidades Autônomas (CA): territórios político-administrativos e geográficos com relativa autonomia da administração central, dotados de competências legislativas e executivas, e que preservam distintas identidades socioculturais. A Espanha conta com $17 \mathrm{CA}$.

Pode-se considerar que o início da reforma espanhola se deu em 1982, com a própria reforma do sistema de saúde e a criação de uma Comissão Ministerial para a Reforma Psiquiátrica no ano seguinte, que, posteriormente, em 1985, apresentou o relatório intitulado Documento General y Recomendaciones para la Reforma Psiquiátrica y la Atención a la Salud Mental, reputado como o Informe da Reforma Psiquiátrica (ESPANHA, 1985, 2007; CARBAJOSA, 2012).

O informe apontava o direcionamento da desinstitucionalização no país e apresentavase estruturado em três eixos orientadores: 1) um novo modelo de atenção à saúde mental, pautado na atenção comunitária e integrada à nova estrutura dos serviços sanitários, 
com ênfase na atenção primária à saúde; 2) um conjunto de recomendações para a reforma psiquiátrica no âmbito das comunidades autônomas; e 3) integração das medidas adotadas às propostas de reforma sanitária. $\mathrm{O}$ documento ainda reconheceu a prioridade da atenção à saúde mental às crianças e aos idosos, às pessoas em situação de privação de liberdade e às pessoas com transtornos mentais decorrentes do uso de drogas, facultando o direito à assistência integral à saúde e à atenção psicossocial (ESPANHA, 1985).

A publicação desse documento foi importante para o desenvolvimento do processo de reforma em todo o território espanhol, visto ter garantido a inscrição da Saúde Mental na Lei Geral de Saúde (LGS), aprovada em 1986, instituindo na Espanha um sistema público de saúde universal, equânime e com financiamento público (DESVIAT, 2011). O art. 20 da referida lei determina a reorientação da saúde mental para o âmbito comunitário, de forma a reduzir ao máximo a necessidade de hospitalização (ESPANHA, 1986).

Segundo Desviat (2011), a grande inovação da reforma psiquiátrica espanhola foi a inclusão da saúde mental nas leis gerais, cujo intuito era não discriminar as pessoas com transtorno mental com uma legislação específica. Dessa forma, as demandas de saúde mental passaram a ser tradadas na esfera do SNS.

Após a publicação do Informe e da LGS, o ministério passou a implementar a reforma por intermédio de algumas medidas; dentre elas, salienta-se a integração da saúde mental ao elenco da atenção especializada do SNS, concebendo a Atenção Primária como porta de entrada para o cuidado, e a criação de serviços de atenção psicossocial sob a coordenação dos serviços sociais. Nesse processo de reforma, os serviços psiquiátricos existentes no país passaram a ser denominados de serviços de saúde mental, evidenciando o caráter conceitual do novo modelo (DESVIAT, 2011).

A nova organização do sistema de saúde promoveu a criação de equipes ambulatoriais para acompanhar o processo de desinstitucionalização e novos programas de saúde, tais como: internação breve em hospital geral, atenção ambulatorial, atenção domiciliar e alternativa de moradia assistidas e residências em saúde mental, além da redução de leitos psiquiátricos e o fechamento de vários hospitais.

A reforma também interferiu na formação psiquiátrica no país, criando as Residências em Psiquiatria, propiciando aos novos residentes experiências em todos os serviços da nova rede, acompanhando diferentes programas e usuários, bem como introduziu a formação em Psicologia Clínica e Enfermagem em Saúde Mental (DESVIAT, 2011).

Depreende-se que, de um modo geral, a estruturação da rede de saúde mental, oriunda do projeto de reforma, assentou-se em dois níveis de atenção: 1) o cuidado ofertado aos sintomas e 2) a atenção psicossocial voltada para a promoção da autonomia das pessoas com transtornos mentais. O primeiro nível encontra-se orientado para os serviços gerais de saúde e especializado, enquanto o segundo, para os programas e serviços de reabilitação psicossocial (CARBAJOSA, 2012). 
Contudo, durante os anos de 1990, a partir das experiências das comunidades autônomas, desenvolveram-se diferentes modelos de atenção psicossocial. Pode-se considerar que a estrutura da reforma sanitária na Espanha, baseada na territorialização da atenção, associada à descentralização das comunidades autônomas, favoreceu o processo de reforma psiquiátrica, mas, ao mesmo tempo, criou uma heterogeneidade da atenção, dadas as características particulares de cada comunidade (CARBAJOSA, 2012; DESVIAT, 2015).

Para Carbajosa (2012), cada comunidade desenvolve seus modelos de gestão, integrando e combinando os níveis de atenção acima citados. Nessa perspectiva, algumas comunidades fazem total distinção entre serviços sanitários e sociais, enquanto outras promovem a integração dos serviços ou mantêm a organização nos dois níveis, sob uma coordenação integrada. Todavia, nesse processo, observou-se que ainda persiste em algumas comunidades a permanência do hospital psiquiátrico, explicitando a dificuldade das administrações locais em absorver a gestão dos serviços sanitários e implementar as diretrizes da reforma.

Dada a característica avançada de sua reforma psiquiátrica, tanto técnica quanto política, mas ao mesmo tempo desigual, o governo espanhol decidiu, por meio do Ministério da Saúde de Política Social, elaborar um plano nacional de saúde mental. Para a sua construção, a gestão central realizou consulta com especialistas, organizações e associações do âmbito da saúde mental para desenhar a sua estrutura. O primeiro plano foi aprovado em 2006 e publicado como Estratégia em Saúde Mental do Sistema Nacional de Saúde, em 2007 (ESPANHA, 2007, 2011).

Essa iniciativa atendeu também às recomendações da Declaração de Helsink, subscrita pela Espanha. A referida declaração resultou da Conferência de mesmo nome realizada em Helsink, Finlândia, com o tema "Enfrentando desafios, construindo soluções em Saúde Mental”. A Declaração chama atenção para a inserção da saúde mental como estratégia prioritária nos sistemas de saúde da Europa e a adoção de um plano de ação para conduzir esse processo, competindo a cada Estado formular e coordenar as estratégias de saúde mental que integrassem a promoção e a prevenção de fatores determinantes e riscos relacionados ao desenvolvimento de transtornos mentais, uso abusivo de drogas e suicídio (ESPANHA, 2011; MONSALVE, 2011).

Dois anos após a implementação da Estratégia Nacional, realizou-se a primeira avaliação, que reconheceu as dificuldades de aprofundamento da reforma psiquiátrica, reordenou alguns objetivos e exibiu uma análise da situação da rede de saúde mental (ESPANHA, 2010). Com base nessa análise, uma nova proposta de ações estratégicas foi elaborada para ser desenvolvida no período de 2009 a 2013.

Tal estratégia surgiu em decurso da necessidade de atualizar o panorama da atenção à saúde mental e reabilitação psicossocial pelo Estado, verificar os avanços promovidos pelo Informe e pela LGS e as desigualdades produzidas na assistência pelas comunidades autônomas, a exemplo da transição lenta dos serviços hospitalares ofertados para a atenção comunitária, e, principalmente, da fragilidade na atenção às pessoas com TMG (MONSALVE, 2011). Todavia, apesar das desigualdades evidenciadas, considera-se que o 
uso das estratégias de combinação da gestão da clínica, com atenção aos sintomas, e suporte psicossocial em uma rede integrada propiciaram um avanço no processo da Reforma Psiquiátrica na Espanha, transformando a experiência em modelo internacional (DESVIAT, 2011, 2015).

Vale destacar que a atenção à saúde mental na Espanha está mais uniformizada entre as comunidades autônomas em razão da Estratégia Nacional. No entanto, a atenção psicossocial, por razões econômicas, políticas, sociais, dentre outras, em algumas comunidades, dispõe de uma rede de atenção mais alargada, abastada em serviços e recursos territoriais, enquanto outras se mostram mais restritas.

De modo geral, as políticas de desinstitucionalização na Espanha estão ativas, tendo proporcionado a superação do modelo asilar e a geração de recursos e programas de atenção psicossocial no âmbito das comunidades.

Porém, não se pode ignorar o avanço das políticas neoliberais nos anos 1990 e seu aprofundamento durante a crise econômica de 2008, impactando fortemente a política de saúde com a imposição de um Estado Mínimo, a redução de gastos sociais e o incremento de políticas e programas para aumentar sua eficiência, assentada na privatização do sistema ou na adoção de modelos mistos. Nessa acepção, as políticas neoliberais têm colocado a saúde como um bem individual, e não como um direito social. Com isso, tem-se promovido a ampliação do processo de medicalização e de psicologização da vida social, com nítidos interesses na mercantilização da saúde (DESVIAT, 2016).

Tais intervenções afetaram os sistemas de saúde e o processo de Reforma Psiquiátrica na Espanha; dentre elas, destacam-se as experiências da Comunidade de Madri e Valência, que entregaram a gestão de todos os serviços sanitários às empresas privadas, convertendo a saúde em um negócio (DESVIAT, 2011). Os efeitos destas políticas têm ampliado as desigualdades sociais e agravado a situação de saúde da população, com forte rebatimento na saúde mental - aumento de ansiedade, depressão, internamentos psiquiátricos e suicídio (SERAPIONE, 2017).

A visão neoliberal sobre a saúde também teve seus efeitos na psiquiatria, produzindo uma psiquiatria ateórica, pautada na evidência científica como forma de justificar sua prática. Além disso, fomentou o reducionismo biológico dos transtornos mentais e a patologização de comportamentos (DESVIAT, 2016). Tais perspectivas estão fortemente relacionadas com o interesse da indústria farmacêutica, além de favorecer a criação de novos campos científicos, como a neurociência. Esse fenômeno tem sido alvo de críticas por estudiosos de diferentes campos disciplinares, até mesmo da própria medicina (GØTZSCHE, 2016; GUARIDO, 2007).

Pode-se considerar que o projeto de reforma na Espanha sofre com o aprofundamento das políticas neoliberais, as quais vêm criando as condições objetivas e subjetivas para o retorno da lógica asilar, fortalecendo tanto o papel do hospital psiquiátrico e da internação quanto o desmonte e a privatização da rede. 


\section{Conclusão}

Após as análises apresentadas, apreende-se que o projeto de reforma psiquiátrica, em ambos os países, implementou suas políticas de desinstitucionalização em um contexto muito semelhante de luta contra a ditatura, construção de suas democracias e definição de um sistema de proteção social que coloca a saúde como direito universal, em um momento em que já ocorria o enfraquecimento do Estado de bem-estar social, assim como a emergência posterior das políticas neoliberais. Mesmo tendo esses aspectos em comum e partilhando a crítica ao modelo asilar, o aprofundamento da reforma enfrentou suas próprias dificuldades, considerando as características particulares de cada país, mas também a inflexão do neoliberalismo. Em mudanças recentes, destacam-se também, nos dois contextos, alterações no âmbito da gestão e da organização da rede, com precarização dos serviços e privatizações, bem como a oferta do cuidado que tende a reatualizar uma abordagem conservadora da saúde mental com ênfase nos TMG, e muitas vezes questionando a abordagem psicossocial. As experiências ainda possuem em comum a influência de outros movimentos e seu início tardio em relações a outros países.

Pode-se afirmar que o projeto de reforma psiquiátrica nos países em análise enfrenta três grandes desafios: 1) desmontar a estrutura manicomial; 2) fortalecer o novo modelo de atenção; 3) combater o modelo asilar que permanece nas práticas profissionais e no imaginário social.

Ambas as experiências reuniram o empenho de vários grupos sociais, como profissionais de saúde, gestores comprometidos com os princípios da reforma e, em certa medida, contaram com a participação de usuários e familiares, compondo grupos de mobilização ou associações. Nesse processo, as políticas de desinstitucionalização ganharam contornos particulares, a partir da conjuntura histórica e das características socioculturais dos dois países, que promoveram diferentes movimentos e modelos de cuidado.

Portanto, ao examinarmos as experiências no Brasil e na Espanha, depreendem-se três processos que merecem posterior análise, a saber: 1) o entendimento do projeto de reforma como um mecanismo de resistência em face do modelo asilar/psiquiátrico operado pelas instituições e pelos atores que a representam, e que ganham força na atual conjuntura; 2) a construção de substrato político, teórico e social em torno da saúde mental, o que pode induzir um conjunto diversificado de práticas em consonância com os processos de desinstitucionalização; e 3) a sistematização das respostas políticas e assistenciais diante do agravamento das questões de saúde mental nos contextos analisados.

Por fim, ressalta-se, ainda, o caráter preliminar desta análise, em virtude de se tratar de pesquisa em andamento, mas que já tem demonstrado os desafios impostos ao projeto de reforma psiquiátrica contemporâneo. 


\section{Referências}

ALVES, Maria de Fátima Pereira. A doença mental nem sempre é doença: racionalidades leigas sobre saúde e doença mental - um estudo no Norte de Portugal. 2008. 398 f. Tese (Doutorado em Sociologia)-Universidade Aberta, Lisboa 2008.

ALMEIDA FILHO, Antônio José de et al. Trajetória histórica da reforma psiquiátrica em Portugal e no Brasil. Revista de Enfermagem Referência, Coimbra, v. 4, n. 4, p. 117-125, 2015. DOI: http://dx.doi.org/10.12707/RIV14074.

AMARANTE, Paulo. Loucos pela vida: a trajetória da Reforma Psiquiátrica no Brasil. 9.ed. Rio de Janeiro: Editora Fiocruz, 2018.

AMARANTE, Paulo. Saúde Mental, Desinstitucionalização e Novas Estratégias de Cuidados. In: GIOVANELLA, L. et al. (org.). Políticas e Sistemas de Saúde no Brasil. 3. ed. Rio de Janeiro: Editora Fiocruz, 2017.

AMARANTE, Paulo; NUNES, Mônica de Oliveira. A reforma psiquiátrica no SUS e a luta por uma sociedade sem manicômios. Ciência \& Saúde Coletiva, Rio de Janeiro, v. 23, n. 6, p. 2067-2074, jun. 2018. DOI: 10.1590/1413-81232018236.07082018. Disponível em: https://www.scielo.br/pdf/csc/v23n6/1413-8123-csc-23-06-2067.pdf. Acesso em: 25 fev. 2020.

BRASIL. Lei no 10.216, de 6 de abril de 2001. Dispõe sobre a proteção e os direitos das portadoras de pessoas com transtornos mentais e redireciona o modelo de assistência em saúde mental. Brasília (DF): Senado Federal, 2001. Disponível em: http://www.planalto.gov.br/ccivil_03/LEIS/LEIS_2001/L10216.htm. Acesso em: 10 fev. 2019.

BRASIL. Ministério da Saúde. Portaria ${ }^{\circ}$ 336, de 19 de fevereiro de 2oo2. Estabelece as modalidades dos CAPS. Brasília (DF), 2002. Disponível em:

https://bvsms.saude.gov.br/bvs/saudelegis/gm/2002/prto336 1902 2002.html. Acesso em: 10 fev. 2019.

BRASIL. Ministério da Saúde. Portaria $\mathbf{n}^{\circ}$ 3.088, de 23 de dezembro de 2011 . Institui a Rede de Atenção Psicossocial para pessoas com sofrimento psíquico ou transtorno mental e com necessidades decorrentes do uso de crack, álcool e outras drogas, no âmbito do SUS. Brasília (DF), 2011. Disponível em: http://bvsms.saude.gov.br/bvs/saudelegis/gm/2011/prt3o88 23122011 rep.html. Acesso em: 10 fev. 2019.

BRASIL. Ministério da Saúde. SAS/DAPES. Coordenação Geral de Saúde Mental, Álcool e Outras Drogas. Nota Técnica no 11/2019. Esclarecimentos sobre as mudanças na Política Nacional de Saúde Mental e nas Diretrizes da Política Nacional sobre Drogas. Brasília: fevereiro de 2019. Disponível em: http://pbpd.org.br/wpcontent/uploads/2019/02/0656ad6e.pdf. Acesso em: 1ำ mar. 2019. 
BRASIL. Ministério da Saúde. SAS/DAPES. Coordenação Geral de Saúde Mental, Álcool e Outras Drogas. Saúde Mental em Dados - 12, Ano 10, n. 12, out. 2015. Disponível em:

https://www.mhinnovation.net/sites/default/files/downloads/innovation/reports/Rep ort_12-edicao-do-Saude-Mental-em-Dados.pdf. Acesso em: 25 mar. 2019.

BRITO, Andiara Araújo Cunegundes de; BONFADA, Diego; GUIMARÃES, Jacileide. Onde a reforma ainda não chegou: ecos da assistência às urgências psiquiátricas.

Physis, Revista de Saúde Coletiva, Rio de Janeiro, v. 25, n. 4, p. 1293-1312, dez. 2015.

DOI 10.1590/So103-73312015000400013. Disponível em:

http://www.scielo.br/scielo.php?script=sci_arttext\&pid=So103-

73312015000401293\&lng=pt\&tlng=pt. Acesso em: 5 fev. 2020.

CARBAJOSA, Adrián Badallo. Estigma y Salud Mental: un modelo de lucha contra el estigma. Madrid: Editorial Grupo 5, 2012.

COSTA-ROSA, Abílio. O Modo Psicossocial: um paradigma das práticas substitutivas ao Modo Asilar. In: AMARANTE, Paulo (org.). Ensaios-subjetividade, saúde mental e sociedade. Rio de Janeiro: Fiocruz, 200o. p. 141-168

DELGADO, Pedro Gabriel. Limites para a inovação e pesquisa na reforma psiquiátrica. Physis, Revista de Saúde Coletiva, Rio de janeiro, v. 25, n. 1, p. 13-18, mar. 2015. DOI 10.1590/So103-73312015000100002. Disponível em:

http://www.scielo.br/scielo.php?script=sci_arttext\&pid=So103-

73312015000100013\&lng=pt\&tlng=pt. Acesso em: 5 fev. 2020.

DESVIAT, Manuel. Cohabitar la diferencia: de la reforma psiquiátrica a la salud mental colectiva. Madrid: Editorial Grupo 5, 2016.

DESVIAT, Manuel. Reforma Psiquiátrica. 2. ed. Rio de Janeiro: Editora Fiocruz, 2015.

DESVIAT, Manuel. La reforma psiquiátrica 25 años después de la Ley General de Sanidad. Revista Española de Salud Pública, Madrid, v. 85, n. 5, p. 427-436, out. 2011. Disponível em: http://www.scielosp.org/scielo.php?script=sci arttext\&pid=S113557272011000500002\&lng=es\&nrm=iso\&tlng=es. Acesso em: 19 jan. 2020.

ESPANHA. Comisión Ministerial para la Reforma Psiquiátrica. Documento General Y Recomendaciones Para La Reforma Psiquiátrica Y La Atención a La Salud Mental.

Revista de la Asociación Española de Neuropsiquiatría, Madrid, n. 13, p. 204-222, 1985. Disponível em:

http://www.revistaaen.es/index.php/aen/article/view/14810/14679. Acesso em: 20 jan. 2020.

ESPANHA. Gobierno de España. Ley 14/1986 de 25 de abril, General de Sanidad.

Boletin Oficial del Estado, p. 1-24, 1986. Disponível em:

https://www.boe.es/buscar/pdf/1986/BOE-A-1986-10499-consolidado.pdf. Acesso em: 20 jan. 2020. 
ESPANHA. Ministerio de Sanidaded, Política Social e Igualdad. Estrategia em Salud Mental del Sistema Nacional de Salud (2009-2013). Madrid: Centro de Publicaciones, 2011. Disponível em:

https://www.mscbs.gob.es/organizacion/sns/planCalidadSNS/saludMental.htm. Acesso em: 5 fev. 2020.

ESPANHA. Ministerio de Sanidad y Consumo. Estrategia en Salud Mental del Sistema Nacional de Salud (2006). Madrid: Centro de publicaciones, 2007. Disponível em:

https://www.mscbs.gob.es/organizacion/sns/planCalidadSNS/saludMental.htm. Acesso em: 5 fev. 2020.

ESPANHA. Ministerio de Sanidad y Política Social. Evaluación de la Estrategia en Salud Mental. Madrid: Centro de Publicaciones, 2010. Disponível em: https://www.mscbs.gob.es/organizacion/sns/planCalidadSNS/saludMental.htm. Acesso em: 16 mar. 2020.

FARIAS, Lara Lisboa. Estado, contrarreforma e as políticas de saúde e saúde mental no Brasil. Argumentum, Vitória, v. 11, n. 3, p. 47-66, 2019. DOI 10.18315/argumentum.vi1i3.22727. Disponível em: https://periodicos.ufes.br/argumentum/article/view/22727/20192. Acesso em: 18 fev. 2020.

GØTZSCHE, Peter. Medicamentos mortais e crime organizado: como a indústria farmacêutica corrompeu a assistência médica [recurso eletrônico]. Porto Alegre: Bookman, 2016.

GUARIDO, Renata. A medicalização do sofrimento psíquico: considerações sobre o discurso psiquiátrico e seus efeitos na Educação. Educação e Pesquisa, São Paulo, v. 33, n. 1, p. 151-161, 2007. DOI 10.1590/S1517-97022007000100010. Disponível em: https://www.scielo.br/scielo.php?pid=S151797022007000100010\&script=sci_abstract\&tlng=pt Acesso em: 17 dez. 2019.

LIMA, Rossano Cabral. O avanço da Contrarreforma Psiquiátrica no Brasil. Physis, Revista de Saúde Coletiva, v. 29, n. 1, p. 1-5, 2019. DOI 10.1590/So103-73312019290101. Disponível em: http://www.scielo.br/scielo.php?script=sci arttext\&pid=So10373312019000100100\&tlng=en. Acesso em: 5 fev. 2020.

LIMA, Telma Cristiane Sasso de; MIOTO, Regina Célia Tamaso. Procedimentos metodológicos na construção do conhecimento científico: a pesquisa bibliográfica. Katálysis, Rio de Janeiro, v. 10, n. especial-Pesquisa em Serviço Social, p. 37-45, 2007. DOI 10.1590/S1414-49802007000300004. Disponível em: http://www.periodicos.ufsc.br/index.php/katalysis/article/view/1030. Acesso em: 31 maio 2020. 
MONSALVE, Mariano Hernández. Rehabilitación psicosocial: perspectiva actual y directrices en la Reforma Psiquiátrica. Estudos de Psicologia, Natal, v. 16, n. 3, p. 295303, dez. 2011. DOI 10.1590/S1413-294X2011000300013. Disponível em:

http://www.scielo.br/scielo.php?script=sci_arttext\&pid=S1413294X2011000300013\&lng=es\&tlng=es. Acesso em: 19 mar. 2020.

ROTHER, Edna Terezinha. Revisão sistemática X revisão narrativa. Acta Paulista de Enfermagem, São Paulo, v. 20, n. 2, p. v-vi, jun. 2007. DOI 10.1590/So10321002007000200001. Disponível em: http://www.scielo.br/scielo.php?script=sci_arttext\&pid=So10321002007000200001\&lng=pt\&tlng=pt.

Acesso em: 10 fev. 2020.

PINHO, Leandro Barbosa de; BAÑON HERNÁNDEZ, Antônio Miguel; KANTORSKI, Luciane Prado. Trabalhadores em saúde mental: contradições e desafios no contexto da reforma psiquiátrica. Escola Anna Nery, Rio de Janeiro, v. 14, n. 2, p. 26o-267, jun. 2010. DOI 10.1590/S1414-81452010000200008. Disponível em: http://www.scielo.br/scielo.php?script=sci arttext\&pid=S141481452010000200008\&lng=pt\&tlng=pt. Acesso em: 3 mar. 2019.

PITTA, Ana Maria Fernandes. Um balanço da reforma psiquiátrica brasileira: instituições, atores e políticas. Ciência \& Saúde Coletiva, Rio de Janeiro, v. 16, n. 12, p. 4579-4589, dez. 2011. DOI 10.1590/S1413-81232011001300oo2. Disponível em: http://www.scielo.br/scielo.php?script=sci_arttext\&pid=S1413$81232011001300002 \& \operatorname{lng}=$ pt\&tlng=pt. Acesso em: 13 dez. 2019.

SERAPIONI, Mauro. Crise econômica e desigualdades nos sistemas de saúde dos países do Sul da Europa. Cadernos de Saúde Pública, Rio de Janeiro, v. 33, n. 9, 28 set. 2017. DOI 10.1590/o102-311xoo170116. Disponível em: http://www.scielo.br/scielo.php?script=sci arttext\&pid=So102311X2017000903001\&lng=pt\&tlng=pt. Acesso em: 17 mar. 2020.

SILVA, Martinho Braga Batista e. Reforma, responsabilidades e redes: sobre o cuidado em saúde mental. Ciência \& Saúde Coletiva, Rio de Janeiro, v. 14, n. 1, p. 149-158, fev. 2009. DOI 10.1590/S1413-81232009000100020. Disponível em: http://www.scielo.br/scielo.php?script=sci arttext\&pid=S141381232009000100020\&lng=pt\&tlng=pt. Acesso em: 3 mar. 2019.

SIQUEIRA-SILVA, Raquel; NUNES, João Arriscado; MORAES, Marcia. Portugal e Brasil no cenário da saúde mental. Fractal, Revista de Psicologia, Rio de Janeiro, v. 25, n. 3, p. 475-496, dez. 2013. DOI 10.1590/S1984-02922013000300005. Disponível em: http://www.scielo.br/scielo.php?script=sci_arttext\&pid=S198402922013000300005\&lng=pt\&tlng=pt. Acesso em: 10 mar. 2019.

WOLF, Paulo José Whitaker; OLIVEIRA, Giuliano. Contento. Os sistemas de proteção social do Brasil e dos países da Europa Meridional: uma análise comparada. Texto para Discussão. Unicamp - IE, Campinas, n. 288, mar. 2017. 
Rafael Nicolau Carvalho Trabalhou na concepção e delineamento do estudo e da redação do artigo. Doutor em Sociologia pela Universidade Federal da Paraíba, com estágio sanduíche no Instituto de Ciências Sociais da Universidade de Lisboa (ICS/UL) em Portugal. Professor Visitante na Universidade de Salamanca.

Antonia Picornell-Lucas Trabalhou na concepção do estudo e da revisão do artigo. Doutora em Educaçao (Universidade de Salamanca, 2003), Graduada em Serviço Social (1992) e Graduada em Filosofia e Ciências da Educaçao (1994) e Fundadora e Presidenta da Red Iberoamericana para la Docencia e Investigación en Derechos de la Infancia [REDidi] (2013). 